\title{
GRADUAÇÃO EM ENFERMAGEM: A CONFIGURAÇÃO DO NOVO CURRÍCULO DA EEUSP
}

Cilene Aparecida Costardi Ide*

IDE, C.A.C. Graduação em enfermagem: a configuração do novo currículo da EEUSP. Rev.Esc.Enf.USP, v.29, n.1, p.104-12, abr. 1995.

O trabalho caracteriza a atual estrutura curricular da graduação, bem como os pressupostos que nortearam essa construção. Tendo a realidade da prática assistencial como substrato, os princípios e diretrizes do Sistema Único de Saúde como referência e as perspectivas de aprimoramento do ensino superior como desafio, a Escola de Enfermagem da Universidade de São Paulo configurou uma nova estrutura de ensino apta a atender às diferentes demandas por aprimoramento do sistema formador em Enfermagem.

Unitermos: Educação em Enfermagem. Processo de ensino.

\section{Introdução}

A política de formação de recursos humanos no âmbito do ensino superior privilegia a reestruturação de cursos pautada no realinhamento crítico de disciplinas, na articulação de conteúdos constituintes, agora, de áreas temáticas, na dinamicidade do processo de ensino, na flexibilidade da estrutura curricular, bem como na promoção de estratégias e de condições que viabilizem e qualifiquem a participação discente na formulação, experimentação e validação dos conhecimentos e habilidades especificas ${ }^{1}$.

Na EEUSP, vimos desenvolvendo atividades de reorientação curricular que culminaram, em 1993, na proposição do novo currículo de graduação, conformando um processo de vivências docentes passíveis de registro e divulgação.

A análise dessa trajetória percorrida pela comunidade da EE possibilita identificar várias etapas significativas em efeitos.

No início, acreditávamos na viabilidade de reformulações pautadas prioritariamente na releitura da prática pedagógica, na reconstrução do vigente privilegiando a esfera das relações e nela na primazia da participação 
discente. Princípio coerente e válido, porém dissonante do esquema hegemônico, tanto no âmbito do $3^{9}$ grau quanto no contexto da formação básica. Concomitantemente, toda uma construção sociologicamente fundamentada de análise e de proposição de intervenções no contexto das práticas em saúde vinha se organizando, num movimento que, pelo teor, também gerou resistências. Ambos tiveram efeito e plantaram raízes. Inviabilizado o retrocesso, mantido o compromisso, aclarado os limites e as possibilidades do grupo, convivendo, agora, com diferenças esplícitas porém não excludentes, avançamos. É provável que, nessa caminhada, tenhamos minimizado a força dos mecanismos psiquicos de defesa, utilizados em reação a situações vivenciadas como estressantes e ameaçadoras, manifestas e percebidas de formas diferentes. Avançamos, desenvolvendo atividades pautadas nas seguintes premissas de atuação:

- a responsabilidade pela coordenação dos trabalhos como prerrogativa e responsabilidade da comissão de graduação, com apoio administrativo e deliberativo da Diretoria da Unidade;

- a participação compartilhada na esfera decisória pautada, porém, num esquema de proposições elaboradas a priori, como substrato para a análise e a validação conjuntas;

- o engajamento de docentes de disciplinas básicas e de representantes da comunidade assistencial como elementos a subsidiarem os trabalhos, cabendo a prerrogativa e a responsabilidade pela elaboração pedagógica a quem de direito, ou seja, ao corpo docente;

- o reconhecimento dos limites como estratégia para propor avanços reais e passíveis de consecução;

- a convivência compartilhada dos riscos inerentes às mudanças.

Nessa dinâmica cabe destacar a significativa atuação discente, buscando apreender e responder às propostas, bem como a qualificada atuação dos funcionários do Serviço de Graduação, enquanto infra-estrutura necessária ao desenvolvimento dos trabalhos cuja versão caracterizaremos a seguir.

Vale enfatizar que a configuração assumida pela estrutura proposta já contempla os pressupostos norteadores do Novo Currículo Mínimo em Enfermagem. Implementa uma modalidade de processo ensino-aprendizagem de cunho inovador na medida em que, considerando as diretrizes e perspectivas dos sistema assistencial e de ensino superior, viabiliza e fundamenta diferentes possibilidades de desenvolvimento discente. Configura-se, assim, um processo planejado e pedagogicamente sustentado para potencializar a autonomia do aluno no sentido de uma formação competente e compatível com um padrão de inserção aprimorado no mercado de trabalho. 


\section{A Configuração da Estrutura Curricular}

Tendo como princípio norteador o compromisso de qualificar a formação do enfermeiro frente aos princípios, diretrizes e práticas do Sistema de Saúde, elaboramos uma estrutura curricular apta a atender também à demandas prementes pelo aprimoramento do processo de ensino, a partir de propostas dentre as quais merecem destaque:

- a redução da carga horária de 4.710 horas para 4.200 horas;

- a inserção de conteúdos teóricos-práticos de Enfermagem a partir do $1^{\circ}$ ano do Curso, na tentativa de diminuir a clistância entre a etapa pré-profissional e o tronco profissional, viabilizando também uma articulação entre as diferentes áreas de saber que subsidiam a profissão;

- um realinhamento em termos de conteúdos e de carga horária das diferentes disciplinas constituintes da Estrutura Curricular, visando a consolidacão de quatro áreas temáticas;

- a redução inicial da carga horária de algumas disciplinas, com a devida complementação no decorrer do curso, a partir de demandas específicas para a fundamentação das áreas temáticas;

- a inclusão gradativa de conteúdos disciplinares relacionados à: Ética e Legislação, Metodologia de Pesquisa e Administração em Enfermagem;

- a criação de novas disciplinas obrigatórias, optativas livres e optativas complementares.

As estratégias anteriormente referidas visam promover a flexibilidade da grade, oferecendo ao aluno a possibilidade e a responsabilidade de organizar a sua inserção num currículo a ser consolidado a partir de expectativas, necessidades e possibilidades peculiares. Nesse sentido, todos os alunos terão que cursar 4.200 horas de graduação. O inédito diz respeito à construção de uma trajetória auto dirigida a partir do $3^{\circ}$ semestre letivo, agregando a opção de entrada numa das quatro áreas temáticas, a serem sucessivamente cursadas; a complementação de conteúdos obtida a partir da escolha de disciplinas optativas livres, dentre o elenco de possibilidades oferecidas, bem como a finalização da sua formação inserindo-se num dos quatro programas de estágio curricular a serem desenvolvidos no último semestre letivo (disciplinas optativas complementares). Este será o período a ser utilizado para a realização de uma monografia, a ser desenvolvida em consonância com as diretrizes da programação do Estágio Curricular.

O novo currículo visa, também, dinamizar o processo de formação, num contexto apto a responder à necessidades peculiares de reformulação, pela inclusão ou deslocamento de conteúdos e práticas a partir da apreensão de diferentes demandas sociais (demandas epidemiológicas, tecnologicas, ine- 
rentes ao processo de trabalho ou ao sistema formador). Assim, pela criação ou exclusão de disciplinas optativas, poderemos mais rapidamente elaborar possibilidades de atender à questões emergentes na esfera da utilização de recursos humanos. Objetiva, ainda, preparar o aluno para uma inserção mais qualificada no seu contexto de atuação a partir do desenvolvimento articulado, gradativo e crescente de conteúdos relacionados à pesquisa, ao exercício profissional (Ética e Legislação) e ao desempenho de atividades peculiares (Administração e Didática).

O novo currículo será composto por 46 disciplinas obrigatórias, 4 disciplinas optativas complementares e 27 disciplinas optativas livres.

A carga horária de 4.200 horas necessária para a conclusão do curso, que compreende um total de 262 créditos, acrescida de 30 horas de Prática Esportiva, deverá ser obtida através da aprovação em 225 créditos $(85,93 \%)$ de disciplinas obrigatórias, 19 créditos $(7,24 \%)$ em uma disciplina optativa complementar e 18 créditos $(6,83 \%)$ em disciplinas optativas de livre escolha do aluno.

Cabe ressaltar que das 46 disciplinas obrigatórias, 8 são novas, 9 permanecem com as mesmas características do currículo vigente e 29 tornar-seão gradativamente equivalentes às disciplinas até então ministradas para permitir a inserção de alunos reprovados ingressantes até o ano de 1993.

Como já foi dito anteriormente, a nova Estrutura Curricular prevê a inserção do aluno à profissão desde o $1^{\circ}$ ano do Curso, através do conjunto composto pelas disciplinas ENC 101 - Introdução à Enfermagem, ENO 100 Fundamentos da Ética e História da Enfermagem e ENS 110 - Introdução à Enfermagem em Saúde Coletiva. Este conjunto subsidiará o ingresso na fase seguinte, ou seja o processo de cuidar em enfermagem, abrangendo conteúdos metodológicos, técnicos, atividades e instrumentos inerentes ao trabalho da Enfermagem e do enfermeiro, contemplando o conjunto composto pelas disciplinas ENC 120 - Fundamentação do processo de cuidar e ENP 152 - Ações Interpessoais Básicas de Saúde Mental.

Do $3^{\circ}$ ao $6^{\circ}$ semestre, 4 áreas temáticas obrigatórias serão oferecidas, todas com a duração de um semestre letivo e repetidas do $3^{\circ}$ ao $6^{\circ}$ semestre, para que o aluno tenha a oportunidade de organizar seu proprio currículo de acordo com suas expectativas, necessidades e possibilidades.

Cada área temática compreenderá inicialmente a matrícula de no máximo 20 alunos e estarão denominadas como segue:

- Área Temática - ENFERMAGEM NA SAÚdE DO ADULTO I, compreendendo as disciplinas - ENC 211 - Enfermagem Médico-Cirúrgica na Saúde do Adulto I, ENC 229 - Enfermagem em Centro de Material, ENC 230 - Enfermagem em Centro Cirúrgico e ENS 240 - Nutrição em Enfermagem no Processo Saúde-Doença do Adulto Trabalhador; 
- Área Temática - ENFERMAGEM NA SAÚDE DO ADULTO II, compreendendo as disciplinas ENP 252 - Enfermagem na Saúde do Adulto II e ENS 318 - Enfermagem em Saúde Coletiva com enfoque nas doenças transmissíveis; - Área Temática - ENFERMAGEM NA SAÚdE DA CRIANÇA E DO ADOLESCENTE, compreendendo as disciplinas ENP 363 - Enfermagem na Saúde da Criança e do Adolescente e ENS 310 - Enfermagem em Saúde Coletiva e a Saúde da Criança e do Adolescente;

- Área Temática - ENFERMAGEM NA SAÚDE DA MULHER, compreendendo as disciplinas ENP 373 - Enfermagem na Saúde da Mulher e ENS 315 Enfermagem na Saúde Coletiva e a Saúde da Mulher.

Concomitante às áreas temáticas, blocos comuns de disciplinas obrigatórias e disciplinas optativas estarão sendo ministrados com períodos específicos, ressaltando-se que durante estes 4 semestres serão destinados também, períodos livres para estudo.

No $7^{\circ}$ semestre, serão ministradas 3 disciplinas obrigatórias, destacando-se que dentre elas inclui-se a ENC 400 - Enfermagem em Terapia Intensiva, criada a partir de necessidades explicitadas pelo corpo discente e que tem entre os seus objetivos a prestação de assistência de enfermagem sistematizada ao paciente internado na UTI.

O último semestre do curso destina-se a realização do Estágio Curricular, onde o aluno poderá escolher uma das quatro disciplinas op tativas complementares.

Esta modalidade compreenderá uma carga horária de 435 horas, sendo 135 para o desenvolvimento de atividades teórico-práticas e supervisão e 300 para o aprofundamento de experiência de coordenação do processo de cuidar e elaboração de monografia em um dos programas oferecidos.

\section{Pressupostos norteadores do Currículo}

A internalização da nova estrutura pressupõe um processo de transformações complementares, estabelecendo novos elos de interação, devendo produzir formas fundamentalmente novas de interpretar e reagir ao currículo, realinhando papéis e o próprio ambiente pedagógico.

Nesse sentido reconstruindo a origem e o curso dessa proposta, vale repontuar os seus pressupostos norteadores, relatados a seguir.

1) A formação de nível superior, enquanto etapa de desenvolvimento profissional do adulto, constitui um processo através do qual o aluno penetra na vida intelectual e no contexto social peculiar à sua área de atuação. Essa concepção deve subsidiar superações reducionistas da capacidade discente, que identificam o aluno ora como um ser infantil, ora como um adulto com 
limitações tidas como insuperáveis. Nesse sentido, um bom aprendizado deverá ser capaz de identificar e utilizar, tanto os ciclos de desenvolvimento cognitivo já completados, como também aqueles em maturação, resultantes da dependência do aluno em desempenhar determinadas atuações.

2) Identificar o aluno como adulto pressupõe estabelecer uma relação pedagógica com uma pessoa apta a dominar processos psicológicos superiores pensamento, linguagem e comportamento volitivo. Um adulto ap to a aprimorar capacidades especializadas para pensar sobre várias coisas.

3) Esse aprimoramento cognitivo - simbólico - afetivo é primordialmente o desenvolvimento de um conjunto de atividades específicas, que se complementarão na medida em que houver elementos comuns entre elas. Elementos elencados a partir de esquemas lógicos a serem sistematicamente explicitados. Pautado nesse argumento, superamos o caráter propedêutico de áreas do cuidar sobre outras. Por isso, também, a confluência de conteúdos complementares às áreas temáticas desde o primeiro ano de graduação, viabilizando o acesso aos códigos de conduta profissional bem como aos instrumentos de pesquisa em concomitância com o domínio gradativo de habilidades específicas. A lógica do encadeamento dos conteúdos se pautou, portanto, no caráter complementar das disciplinas na medida em que todas incluem, igualmente, processos de dedução, compreensão, evolução de noções, interpretação de casualidade, domínio de práticas e de códigos de atuação peculiares.

4) À graduação caberia subsidiar uma etapa peculiar desse desenvolvimento, levando o aluno à resolução, de forma independente, de problemas cada vez mais avançados. Essa é a compreensão que temos de complexidade, independente da área ou de conteúdos. Nesse sentido, o bom aprendizado será aquele que conseguir se adiantar aos ciclos de desenvolvimento já completados por esse aluno. Será que ele apto a aģilizar o nível potencial de desenvolvimento desse aluno, determinado pela dependência de atuações. Essa seria a categoria a definir estratégias específicas para alunos específicos, culminando, ao final do $4^{\circ}$ ano, porém, por caminhos peculiares, num patamar basal para todos.

5) O desenvolvimento rumo a essa autonomia responsável, fundamentada e compatível com o nível de graduação pressupõe a superação gradativa de esquemas concretos, a superação da adesão a códigos de prioridades externas estranhas ao momento e à necessidade de aprendizado. Em decorrência, essa seria a possibilidade do professor efetivamente consolidar o seu espaço no contexto assistencial. Espaço além da lógica das rotinas institucionais e da sujeição a relações de poder estranhas ao seu contexto. Emancipação decorrente da sua identidade acadêmica, ou seja, da intervenção organizada a 
partir da questão teórica central que configura e norteia o seu universo de investigação no âmbito do cuidar. Aqui, também, o espaço do aluno desenvolver sua atividade consciente, característica primordial do desenvolvimento cognitivo do adulto. Aqui, a oportunidade do aluno internalizar experiências vivenciadas em conjunto, assumidas por vontade, gerando um aprendizado pautado na experimentação e não na repetição esvaziada de sentido e de significados. Esse aprendizado seria produto da internalização do vivenciado, da sua reinterpretação, transformando a experiência num processo intrapessoal, capaz de gerar novos sistemas e novas leis de atuação. Aqui, portanto, a identidade complementar do ser aluno e do ser docente de graduação em compatibilidade com a estrutura curricular proposta. Para dar-lhe vida temos como desafio a identificação e implementação de estratégias aptas a:

a) identificar demandas por desenvolvimento cognitivo afetivo dos alunos:

b) potencializar o desenvolvimento daquilo que intrinsicamente estiver faltando no aluno, ou seja, a zona de desenvolvimento proximal ${ }^{2}$;

c) promover a capacidade do aluno optar e buscar experiências compatíveis com suas expectativas, necessidades e possibilidades de momentos,construindo um caminho peculiar no esquema formal da graduação;

d) potencializar a adesão docente ao papel de pesquisador, mais do que uma necessidade, um dever inerente à sua permanência na universidade;

e) trabalhar numa reinserção no campo, a partir de um esquema lógico de atuação por ele estabelecido considerando tanto a sua atividade acadêmica como também a realidade e a demanda desse campo. Nesse sentido, estaríamos promovendo códigos de relacionamento pautados na complementariedade e no respeito d̀ especificidade dos papéis. Estaríamos, ainda potencializando a necessidade de sintonizar a produção acadêmica às etapas de validação na prática assistencial;

f) reconsiderar o interstício entre diferentes áreas, com ênfase nas relações entre o cuidar individual e coletivo, entre a coodenação do cuidar e a administração de serviços;

g) elencar disciplinas a partir do cunho complementar de seus conteúdos, construindo núcleos temáticos efetivamente pautados em abordagens similares;

h) validar um novo padrão de relacionamento docente. A inserção no campo, quando pautada apenas em lógicas externas à produção acadêmica fragiliza a atuação do professor, gerando desgaste, estagnação, desencanto e negação do papel. Em decorrência, dá-se o afastamento, a que 
bra de vínculos com a graduação, concomitantemente d̀ adesão aos esquemas burocráticos. Em decorrência emerge a produção de justifica tivas, enquanto mecanismo capaz de, ao mesmo tempo, minimizar alguns desgastes às custas da geração de uma outra gama de conflitos inerentes, agora, à relação entre os próprios docentes no contexto da atuação acadêmica. Repensar o processo como um todo, viabilizando uma forma de atuação consoante ao ser docente passa a ser, portanto, não somente uma prioridade para sanar atritos como também e primordialmente, um quesito para adequar a política de captação e utilização de novos docentes, e

i) elaborar um processo de avaliação capaz de acompanhar e retroalimentar a dinâmica de implementação dessa cultura.

\section{Considerações finais}

A nova Estrutura Curricular retrata as perspectivas que a Escola de Enfermagem propõe para a graduação. A sua consolidação pressupõe, agora a continuidade de uma nova etapa de atividades a serem mediadas pela comissão de graduação e que dizem respeito ao desenvolvimento de um trabalho sistematizado de estratégias relacionadas à viabilização do processo de ensino proposto. Nesse sentido, destacamos a seguir aspectos considerados como prioritários para a operacionalização dessa estrutura:

- um programa de seguimento curricular, incluindo o acompanhamento dos futuros egressos;

- uma política de recursos humanos no sentido de captação e aprimoramento docente;

- um projeto que tenha como objeto de análise a especificidade do processo de ensino de 30 grau em Enfermagem;

- novas estratégias de articulação entre a Escola e os diferentes campos de prática utilizados pela graduação.

IDE, C.A.C. Nursing graduation: the up date EEUSP curriculum caracterization. Rev.Esc.Enf.USP, v.29, n.1, p.104-12, Apr. 1995.

The research shows the up date curriculum of nursing Graduation and the basis of this proposition.

UNITERMS: Nursing education. Teaching process. 


\section{REFERÊNCIAS BIBLIOGRÁFICAS}

UNIVERSIDADE DE SÃO PAULO. Faculdade de Educação. Problemas e Perspectivas do ensino nos cursos de graduaç̃o da SP/Universidade de São Paulo. São Paulo, 1990 (Documentos especiais n.1).

VYG()TSKY, L.S. A formação social da mente: o desenvolvimento dos processos psicológicos superiores. 4 ed. São Paulo, Martins Fontes, 1991. 